\title{
Development of Photo-sensitive Siloxane Coatings with High Light-diffusion
}

\author{
Hideyuki Kobayashi", Yusuke Fukuzaki, and Mitsuhito Suwa \\ Electronic and Imaging Materials Research Laboratories, \\ Toray Industries, Inc., \\ 1-2, Sonoyama 3-chome, Otsu, Shiga 520-0842, Japan \\ *hideyuki.kobayashi.a2@mail.toray
}

\begin{abstract}
New self-luminous displays such as organic light-emitting diode and micro light-emitting diode devices are attracting increasing attention. Moreover, many researchers are working to improve the light extraction efficiency of these devices to increase the display brightness. Proposed light extraction methods include refractive index control layers, controlled surface texture structures, and light-diffusion layers. Of these, our focus was on the light-diffusion layer, which requires suitable light diffusion, high transparency, high light resistance, and patternability for forming wiring connection areas. In this paper, we introduce novel photosensitive siloxane coatings using positive-tone photosensitive siloxane and a lightdiffusion filler $\left(\mathrm{TiO}_{2}\right.$ or $\left.\mathrm{ZrO}_{2}\right)$. These coatings control the haze value in the range of $5 \%$ to $72 \%$ in the form of a thin film $(1 \mu \mathrm{m})$. In addition, the films have a high transparency, good light resistance, and appropriate patternability. Therefore, these photosensitive siloxane coatings with light-diffusion properties are suitable for new self-luminous displays.
\end{abstract}

Keywords: Positive-tone photosensitive, Light-diffusion, Siloxane coating

\section{Introduction}

Much recent interest has been focused on new self-luminous displays such as organic lightemitting diode (OLED) and micro light-emitting diode ( $\mu$-LED) devices. In these displays, each pixel itself emits light, meaning that no backlight is needed like that required for current liquid crystal displays (LCDs). Therefore, self-luminous displays are advantageous in terms of reduced device thickness and weight (Fig. 1). On the other hand, it has been reported that some of the emitted light remains in the pixel due to total reflection at the interface (Fig. 2). For this reason, many research efforts have been devoted to improving the light extraction efficiency from each pixel. Proposed methods for light extraction include refractive index control layers, controlled surface texture structures, and light-diffusion layers [1,2].

We focused on light-diffusion layers, which require appropriate light diffusion to improve the light extraction efficiency and provide uniform light emission (Fig. 3). In addition, this layer requires high transparency, good light resistance, and patternability to form a wiring connection area for application to image displays.

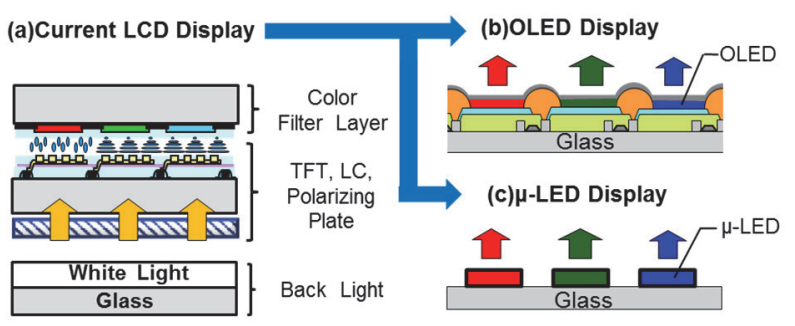

Fig. 1. Example structures of a (a) current LCD display, (b) OLED display, and (c) $\mu$-LED display.

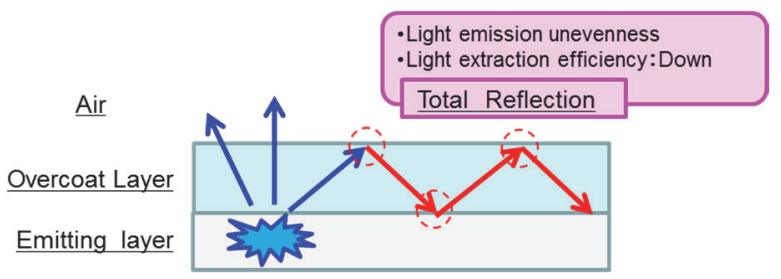

Fig. 2. Mechanism of low light extraction efficiency from internal reflection. 


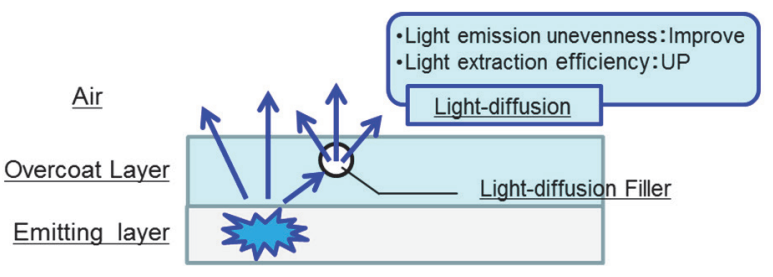

Fig. 3. Functional image of light-diffusion filler.

Previously, we developed siloxane with a high transparency and high light resistance [3-5], and recently, we mass-produced functional composite materials with positive-tone photosensitive siloxane and inorganic filler [6]. In this paper, we introduce novel coatings composed of positive-tone photosensitive siloxane and a light-diffusion filler $\left(\mathrm{TiO}_{2}\right.$ or $\left.\mathrm{ZrO}_{2}\right)$. These photosensitive siloxane coatings are suitable for new self-luminous displays since they offer light-diffusion controllability, high transparency, good light resistance, and suitable patternability.

\section{Experimental}

\subsection{Materials}

We prepared the five types of photo sensitive siloxane coatings shown in Table 1.

Table 1. Composition of photosensitive siloxane coatings.

\begin{tabular}{|c|c|c|c|c|c|c|c|c|}
\hline & & & & \multicolumn{5}{|c|}{ Photosensitive siloxane coatings } \\
\hline & & & & (a) & $\left(b-x^{*}\right)$ & $\left(c-x^{*}\right)$ & $\left(d-x^{*}\right)$ & $\left(e-x^{*}\right)$ \\
\hline \multirow{8}{*}{ 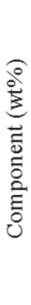 } & \multicolumn{3}{|c|}{ Siloxane polymer } & 92 & 92 & 92 & 92 & 92 \\
\hline & \multicolumn{3}{|c|}{ Photosensitizer } & 8 & 8 & 8 & 8 & 8 \\
\hline & \multicolumn{3}{|c|}{ Light diffusion filler } & & & & & \\
\hline & $\begin{array}{l}\text { Pigment } \\
\text { species }\end{array}$ & $\begin{array}{l}\text { Average } \\
\text { filler size }\end{array}$ & $\begin{array}{c}\text { Refractive } \\
\text { index }\end{array}$ & & & & & \\
\hline & $\mathrm{TiO}_{2}(\mathrm{~A})$ & $295 \mathrm{~nm}$ & 2.71 & - & $5 \sim 20$ & - & - & - \\
\hline & $\mathrm{TiO}_{2}(\mathrm{~B})$ & $15 \mathrm{~nm}$ & 2.71 & - & - & $5 \sim 20$ & - & - \\
\hline & $\mathrm{ZrO}_{2}$ & $305 \mathrm{~nm}$ & 2.13 & - & - & - & $5 \sim 20$ & - \\
\hline & $\mathrm{BaSO}_{4}$ & $298 \mathrm{~nm}$ & 1.64 & - & - & - & - & $5 \sim 20$ \\
\hline
\end{tabular}

* $\mathrm{X}$ is changed 1 to 4 at the additive rate of light-diffusion fillers.

(a): Photosensitive siloxane coating.

(b-1)-(b-4): Photosensitive siloxane coatings with $\mathrm{TiO}_{2}$ pigment $\mathrm{A}$ at $5,10,15$, and 20 $\mathrm{wt} \%$, respectively.

(c-1)-(c-4): Photosensitive siloxane coatings with $\mathrm{TiO}_{2}$ pigment $\mathrm{B}$ at $5,10,15$, and 20 $\mathrm{wt} \%$, respectively.

(d-1)-(d-4): Photosensitive siloxane coatings with $\mathrm{ZrO}_{2}$ pigment at $5,10,15$, and $20 \mathrm{wt} \%$, respectively.

(e-1)-(e-4): Photosensitive siloxane coatings with $\mathrm{BaSO}_{4}$ pigment at $5,10,15$, and 20 $\mathrm{wt} \%$, respectively.

The siloxane polymer was synthesized by the following steps.

1) Hydrosilylation of trimethoxy (methyl) silane, trimethoxy (phenyl) silane, and tetramethoxysilane at a fixed monomer ratio.

2) Condensation of monomers with acid catalysis and removal of catalyst.

The naphthoquinone diazide compound (PHAP280) used as a photosensitizer was purchased from Toyo Gosei. The refractive indices in Table 1 are typical values of the light-diffusion fillers measured at a wavelength of $550 \mathrm{~nm}$.

\subsection{Patterning process}

The photosensitive siloxane coatings were deposited by spin-coating (MS-A100, Mikasa) on glass substrates to obtain a post-curing thickness of $1 \mu \mathrm{m}$. The spin-coated substrates were dried at 100 $\mathrm{Pa}$ for $60 \mathrm{~s}$ in a vacuum dryer (Micro Engineering), then baked at $90{ }^{\circ} \mathrm{C}$ for $180 \mathrm{~s}$ on a hot plate (HPD3000BZN, AZ One). After baking, the film thickness was measured using a surface profiler (Dektak-150, Bruker Nano).

The baked substrates were then exposed with an aligner ( $g, h, i$-line, PLA-501F, Canon) at 1 to 100 $\mathrm{mJ} / \mathrm{cm}^{2}$ (calculated by the $i$-line value) through a mask with a gap of $0 \mu \mathrm{m}$. The mask has a one-line and one-space patterning in the range of 5 to $50 \mu \mathrm{m}$. The exposed substrates were developed by a $2.38 \%$ aqueous solution of tetramethylammonium hydroxide (AD-1200, Takizawa-sangyo). After development, the film thickness was measured by the surface profiler. The developed substrates were finally cured at $170{ }^{\circ} \mathrm{C}$ for 30 min under an air atmosphere in an oven (DN43HI, Yamato Scientific).

\subsection{Evaluation}

The haze values and transmittance at $550 \mathrm{~nm}$ of the cured films $(1 \mu \mathrm{m})$ on glass substrates were measured with spectrometers (NDH-5000, Nippon Densyoku and MCPD-9800, Otsuka Electronics, respectively). To test the resistance to light degradation, the cured films were treated with a Xe lamp $\left(0.6 \mathrm{~W} / \mathrm{m}^{2}, 45^{\circ} \mathrm{C}, 100 \mathrm{~h}\right)$. The refractive index at $550 \mathrm{~nm}$ of the siloxane cured film on glass substrates was measured by ellipsometer (FE-5000, Otsuka Electronics).

We further evaluated the photosensitivity, resolution, and pattern profiles of the cured films. Photosensitivity was evaluated at $E_{\text {th }}$ (exposure dose threshold), which is the lowest exposure dose necessary for complete development. The resolution was defined as the smallest developed pattern size 
at an exposure 1.5 times that of $E_{\text {th }}$. The pattern profiles were observed with scanning electron microscopy (SEM; S-4800, Hitachi).

\section{Results and discussion}

3.1. Haze value

We evaluated the haze values of photosensitive siloxane coatings (a)-(e) (Fig. 4). First, we confirmed that the haze value increased with the

(a)

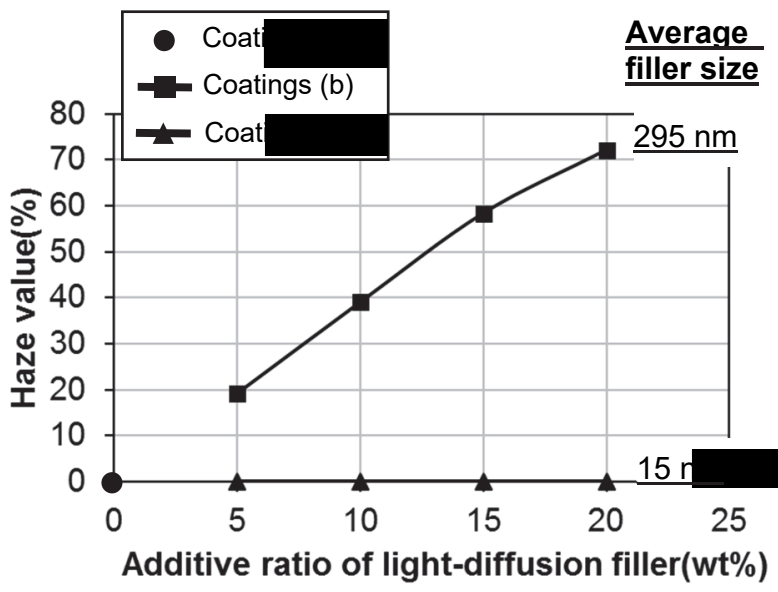

(b)

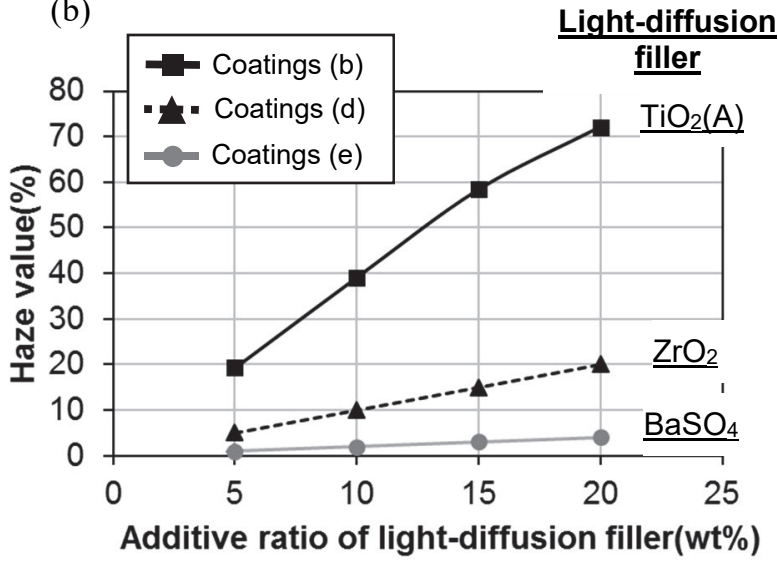

Fig. 4. Haze values of photosensitive siloxane coatings (a)-(e).

(a) Effect of light-diffusion filler size.

(b) Effect of light-diffusion filler species.

Table 2. Refractive index differences between siloxane and light-diffusion fillers.

\begin{tabular}{|c|c|c|c|}
\hline \multicolumn{2}{|c|}{} & $\begin{array}{c}\text { Refractive } \\
\text { index }\end{array}$ & $\begin{array}{c}\text { Refractive index difference } \\
\text { between siloxane and } \\
\text { light-diffusion filler }\end{array}$ \\
\hline Polymer & Siloxane & 1.53 & - \\
\hline \multirow{2}{*}{$\begin{array}{c}\text { Light- } \\
\text { diffusion } \\
\text { filler }\end{array}$} & $\mathrm{TiO}_{2}$ (A) & 2.71 & 1.18 \\
\cline { 2 - 4 } & $\mathrm{ZrO}_{2}$ & 2.13 & 0.60 \\
\hline
\end{tabular}

amount of light-diffusion filler. Then, based on the results for coatings (b) and (c), the haze value increased with the size of the light-diffusion filler (Fig. 4(a)). This is probably due to Mie scattering, which occurs when the filler size is close to the wavelength of the incident light. $\mathrm{TiO}_{2}$ filler (A) shows a high haze value since the filler size is close to the wavelength of the incident light. Then, the results of coatings (b), (d), and (e) showed that the haze value also depended on the light-diffusion filler species (Fig. 4(b)). This is why the degree of Mie scattering is proportional to the refractive index difference between the polymer and light-diffusion filler, as shown in Table 2. $\mathrm{TiO}_{2}$ filler (A), with the highest refractive index, had a high haze value. On the other hand, $\mathrm{BaSO}_{4}$, with the lowest refractive index, had the smallest haze value less than $4 \%$. This haze value is very small and $\mathrm{BaSO}_{4}$ is not suitable for haze value control. Thus, we selected $\mathrm{TiO}_{2}$ or $\mathrm{ZrO}_{2}$, which have an average filler size of approximately $300 \mathrm{~nm}$, as light-diffusion fillers to control the haze value easily in the form of a thin film $(1 \mu \mathrm{m})$.

\subsection{Lithographic performance}

We evaluated the lithographic performance of photosensitive siloxane coatings (a), (b-1), (b-4), and (d-4). First, the photosensitivity results for coatings (a) and (b-4) are shown in Fig. 5, and the corresponding resolution and pattern profiles are shown in Fig. 6. These two coatings are examples with significantly different haze values. Then, the overall results for coatings (a), (b-1), (b-4), and (d4) are given in Table 3. All the results show that these photosensitive siloxane coatings have a high photosensitivity and suitable patternability.

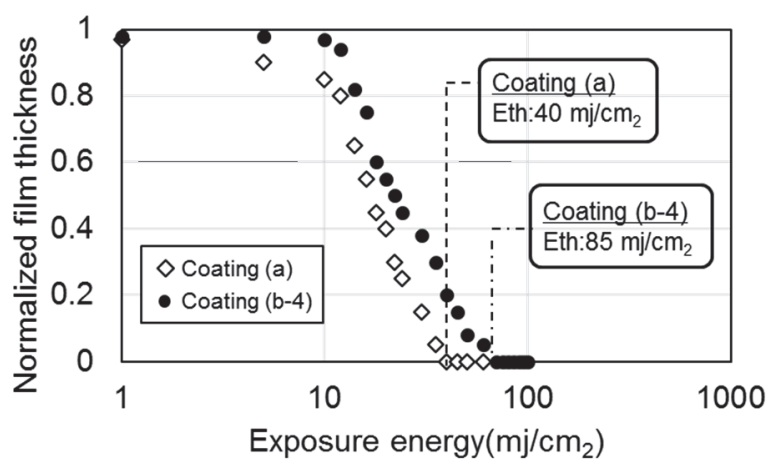

Fig. 5. Exposure dose dependency of photosensitive siloxane coatings (a) and (b-4). 


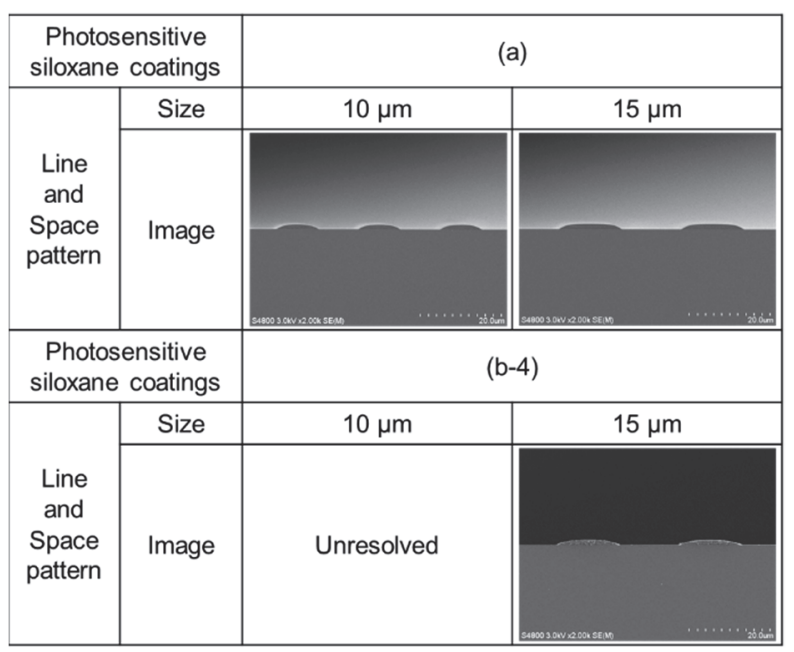

Fig. 6. Cross-sectional view of photosensitive siloxane coatings (a) and (b-4).

Table 3. Lithographic performance of photosensitive siloxane coatings (a), (b-1), (b-4), and (d-4).

\begin{tabular}{|c|c|c|c|c|c|}
\hline \multicolumn{2}{|c|}{} & \multicolumn{2}{|c|}{ Light-diffusion filler } & \multicolumn{2}{c|}{ Lithographic performance } \\
\cline { 2 - 6 } \multicolumn{2}{|c|}{} & Species & $\begin{array}{c}\text { Additive } \\
\text { ratio(wt\%) }\end{array}$ & $\begin{array}{c}\text { Photosensitivity } \\
\left(\mathrm{mi} / \mathrm{cm}_{2}\right)\end{array}$ & $\begin{array}{c}\text { Resolution } \\
(\mu \mathrm{m})\end{array}$ \\
\hline \multirow{3}{*}{$\begin{array}{c}\text { Photosesnsitive } \\
\text { siloxane coatings }\end{array}$} & (a) & - & 0 & 40 & 10 \\
\cline { 2 - 6 } & (b-1) & $\mathrm{TiO}_{2}$ (A) & 5 & 60 & 15 \\
\cline { 2 - 6 } & (b-4) & $\mathrm{TiO}_{2}$ (A) & 20 & 85 & 10 \\
\cline { 2 - 6 } & (d-4) & $\mathrm{ZrO}_{2}$ & 20 & 65 & 10 \\
\hline
\end{tabular}

\subsection{Light irradiation reliability}

We evaluated the effects of light irradiation on photosensitive siloxane coatings (a), (b-1), (b-4), and (d-4) by exposure to a Xe lamp for $100 \mathrm{~h}$. The transmittance at $550 \mathrm{~nm}$ and haze value before and after Xe lamp irradiation are shown in Fig. 7. The transmittance and haze value hardly changed in all the samples after irradiation, indicating that these coatings have a good resistance to light degradation.

\section{Conclusion}

We developed novel light-diffusion coatings using positive-tone photosensitive siloxane and a light-diffusion filler $\left(\mathrm{TiO}_{2}\right.$ or $\left.\mathrm{ZrO}_{2}\right)$. These coatings control the haze value in the range of $5 \%$ to $72 \%$ in the form of a thin film $(1 \mu \mathrm{m})$. In addition, they have a high transparency, good light resistance, and suitable patternability. Therefore, these photosensitive siloxane coatings with lightdiffusion properties are suitable for new selfluminous displays.

\section{References}

1. J. Tanaka, M. Morimoto, T. Kawai, F. Kajikawa, T. Yoshida, and J. Suzuki, Mitsubishi Heavy Industries Tech. J., 51 (2014) 88. (a)

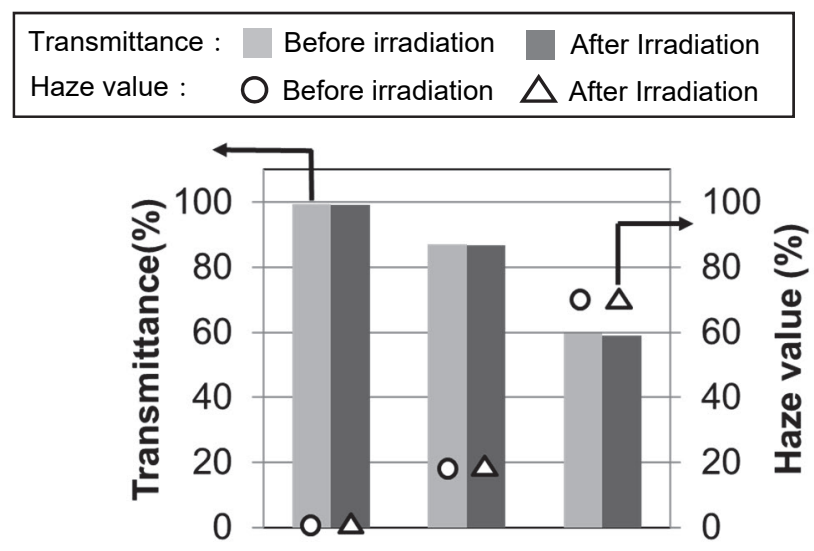

\begin{tabular}{l|ccc}
\hline $\begin{array}{l}\text { Photosensitive } \\
\text { siloxane coatings }\end{array}$ & (a) & $(\mathrm{b}-1)$ & $(\mathrm{b}-4)$ \\
\hline $\begin{array}{l}\text { Additive ratio of } \\
\mathrm{TiO}_{2}(\mathrm{~A})\end{array}$ & $0 \mathrm{wt} \%$ & $5 \mathrm{wt} \%$ & $20 \mathrm{wt} \%$ \\
\hline
\end{tabular}

(b)

\begin{tabular}{|ll}
\hline Transmittance : & Before irradiation \\
Haze value : & $\mathrm{O}$ Bfter Irradiation \\
\hline
\end{tabular}

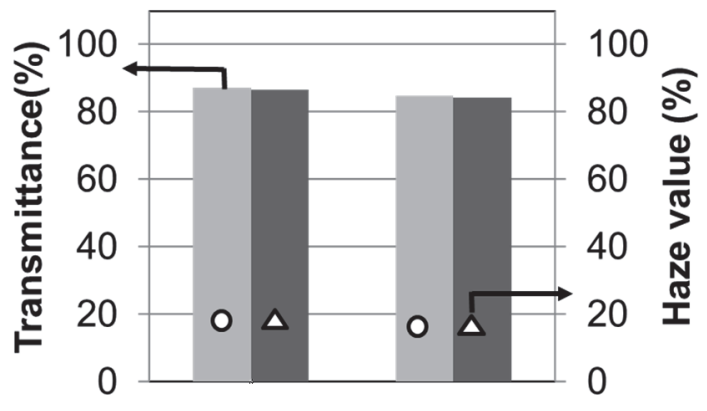

\begin{tabular}{l|c|cc}
\hline $\begin{array}{l}\text { Photosensitive } \\
\text { siloxane coatings }\end{array}$ & (b-1) & $(\mathrm{d}-4)$ \\
\hline $\begin{array}{l}\text { Light- } \\
\text { diffusion } \\
\text { filler }\end{array}$ & Species & $\mathrm{TiO}_{2}(\mathrm{~A})$ & $\mathrm{ZrO}_{2}$ \\
\cline { 2 - 4 } & $\begin{array}{c}\text { Additive } \\
\text { ratio }\end{array}$ & $5 \mathrm{wt} \%$ & $20 \mathrm{wt} \%$ \\
\hline
\end{tabular}

Fig. 7. Light irradiation reliability of photosensitive siloxane coatings. (a) Effect of $\mathrm{TiO}_{2}$ content. (b) Effect of filler species.

2. K. Yamae, H. Tsuji, V. Kittichungchit, Y. Matsuhisa, N. Ide, and T. Komoda, Panasonic Tech. J., 57 (2012) 284.

3. M. Suwa, T. Fujiwara, T. Okazawa, and H. Araki, J. Photopolym. Sci. Technol., 24 (2011) 259.

4. T. Okazawa, K. Ono, and M. Suwa, J. Photopolym. Sci. Technol., 25 (2012) 349.

5. E. Iizuka, H. Kobayashi, and M. Suwa, J. Photopolym. Sci. Technol., 32 (2019) 665.

6. T. Hibino, M. Naruto, Y. Imanishi, and M. Suwa, J. Photopolym. Sci. Technol., 32 (2019) 485. 